\title{
3D-Printed Model of the Ovine Stomach by Surface Scanning: Evaluation for Teaching Veterinary Anatomy
}

\author{
Modelo Impreso en 3D del Estómago Ovino Mediante Escaneo de Superficie: \\ Evaluación para la Enseñanza de Anatomía Veterinaria
}

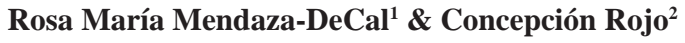

MENDAZA-DECAL, R. M.\& ROJO, C. 3D-printed model of the ovine stomach by surface scanning: Evaluation for teaching veterinary anatomy. Int. J. Morphol., 39(5):1480-1486, 2021.

SUMMARY: This study investigated the use of fused deposition modeling (FDM), three-dimensional (3D) printed models, of the ovine stomach to learn surface and topographical anatomy. The objectives were: i) to faithfully reproduce the external morphology, the normal volume and the correct positioning of the four compartments of the stomach ii) to facilitate students the spatial visualization of the organ with emphasis on the complex relationship stomach-greater omentum. The model was built based on surface scanning. To obtain the images the ovine stomach was scanned using a 3D surface scanner. Assessment of the model was performed through surveys to first-year veterinary students after the practical sessions in which, they studied and compared both real and 3D-printed specimens. Regarding morphology no significant differences were reported, students were equally able to identify the different structures and compartments on the 3D-printed model. Understanding of both spatial position and relationship of the stomach with neighboring anatomical structures was easier achieved with the 3D-printed model. Other advantages of the 3D-printed model were handle-resistance and ease of handling, availability and reduction of animal specimens. We propose that 3D-printed ovine stomach by surface scanning is a valuable simple model to support learning of surface and topographical anatomy.

KEY WORDS: 3D printing scan; Ovine stomach; Veterinary anatomy.

\section{INTRODUCTION}

Acquiring anatomical knowledge of animal structures and the ability to put the knowledge into practice within the clinical context is essential in veterinary medicine. In animal anatomy, production of high-quality 3Dprinted replicas of cadaveric material has rapidly expanded for teaching purposes (Preece et al., 2013; Hespel et al., 2014; Thomas et al., 2016; Raffan et al., 2017; SchoenfeldTacher et al., 2017; Hackmann et al., 2019; Wilhite \& Wölfel, 2019; Di-Donato et al., 2021). In these studies, the educational effectiveness and easy accessibility of 3Dprinted models are emphasized, together with their value as a fair and more ethical alternative to dissected organs and tissues, therefore reducing animal use. Physical models have been considered especially useful to learn gross anatomy (Yammine \& Violato, 2016; Wilhite \& Wölfel) as well as to assist spatial abilities in the learning process (Preece et al.). In a comprehensive review by Ford \&
Minshall (2019) was reported the importance of physical objects, compared with digital models, to bring new elements into view during learning, and showed that 3D-printed artifacts are used to support teaching in anatomy the most. Another review by Azer \& Azer (2016) presented 3D-printed physical anatomy models as preferred by students of medical subjects and concluded that 3D-printed models are useful to support the curriculum and enhance student's skill in spatial visualization of anatomical relationships. It is well known that spatial visualization is of great importance in anatomy (Azer \& Azer; Keenan \& Ben Awadh, 2019). Learning of ruminant's stomach anatomy involves not just comprehension of structures and function but also the dimension of this complex organ and its spatial relationships to surrounding elements. Ruminant stomach consists of four compartments: Rumen, reticulum, omasum (globally called forestomachs) and abomasum (glandular stomach); for

\footnotetext{
${ }^{1}$ Departamento de Medicina y Cirugía Animal. Facultad de Veterinaria, Universidad Complutense de Madrid. Avda. Puerta de Hierro S/N 28040, Madrid, España

${ }^{2}$ Sección Departamental de Anatomía y Embriología. Facultad de Veterinaria. Universidad Complutense de Madrid. Avda. Puerta de Hierro S/N 28040, Madrid, España
} 
anatomy review see Nickel et al. (1979) and König \& Liebich (2011); for anatomical terminology follows that of the International Committee on Veterinary Gross Anatomical Nomenclature (2017). Collectively, these organs occupy almost 3/4ths of the abdominal cavity, filling virtually all the left side and extending significantly into the right. The rumen is in contact with the left abdominal wall and is by far the largest of the three forestomachs. It is itself sacculated by muscular pillars into the following sacs: dorsal, ventral, cranial (atrium), blind caudodorsal and blind caudoventral sacs. The internal pillars correlate externally with marked grooves that contain vessels and nerves protected by fat. The greater omentum (Omentum majus) joins to the longitudinal grooves of the rumen and forms the omental bursa (Bursa omentalis), which inside includes the ventral sac of the rumen. In addition, the greater omentum forms the supraomental recess (Recessus supraomentalis) which contains the intestinal mass. The supraomental recess is situated in the right side of the abdominal cavity. Learners normally find difficult to understand and visualize these structures and their relationships. The reticulum is the most cranial compartment, lies against the diaphragm and is joined caudally to the rumen and connected to the right with the omasum by a short tunnel. The omasum locates to the right side of the abdominal cavity, is smaller than the reticulum and connects with the last compartment, the abomasum, which is located ventrally and to the right in the abdominal cavity.

The aim of the present study was to build and evaluate a 3D-printed model of the ovine stomach by surface scan, comparing with the real organ for the study of surface morphology and topography.

\section{MATERIAL AND METHOD}

Samples. Fresh ovine stomachs (from lambs about 4 months old) were collected from slaughterhouses of Madrid according to standard protocols under sanitary regulation; ethical permissions were not required. Stomachs included a section of esophagus and duodenum.

Manufacturing of the 3D-printed model of the ovine stomach. After insuflation with gas, the stomach was hung from a metal support that allowed turn around the model for scanning the whole surface. 3D scanning was taken with a handheld surface scanner with USB power (3D SENSE Scan, 3D systems Inc., South Carolina, USA).

Data collected from the 3D-surface scanning were processed with the software 3D Systems Sense (version
2.0.321) for reassure a whole connected stomach mesh, which was provided by the 3D scanner company, and Autodesk Meshmixer freeware (Autodesk, California, USA), to obtain a solid and hollow mesh of the stomach.

The 3D-virtual model was prepared for 3D-printing by Fused Deposition Modeling (FDM) using the slicer program of Simplify 3D (Cincinnati, USA). For printing the model, we used polylactic acid (PLA), more specifically Ivony White, $1000 \mathrm{~g}$ spool and $1.75 \mathrm{~mm}$ diameter (Smart Materials, Jaén, Spain). Parameters used for printing are shown in Table I. 3D replicas were printed using a Titan 300 printer (provided by Abax Innovation Technologies, Madrid, Spain). Printing time had a duration of $96 \mathrm{~h}$.

Table I. Printing parameters for each part of the ovine stomach.

\begin{tabular}{ll}
\hline Printing parameters & \\
\hline Extrusion multiplier & 1.03 \\
Layer Height & $0.3 \mathrm{~mm}$ \\
Top, bottom solid layers, and perimeter & 3 \\
Infill & $15 \%$ \\
Support & Yes \\
Nozzle temperature & $210^{\circ} \mathrm{C}$ \\
Printed temperature & $50{ }^{\circ} \mathrm{C}$ \\
Cooling & $60 \%$ since $2 \mathrm{n}^{\mathrm{d}}$ lay \\
Default speed & $50 \mathrm{~mm} / \mathrm{s}$ \\
\hline
\end{tabular}

Context of the study and study participants. There were several reasons for the decision to introduce 3D-printed ovine stomachs in the anatomy labs. First, the need to clarify characteristics of volume and topography. Second, to show the entire organ which can be incomplete due to manipulation in the slaughterhouses. Third, to facilitate the students the manipulation of the organ. Therefore, the objectives by printing $3 \mathrm{D}$ ovine stomachs were: i) to reproduce the external morphology as accurately as possible, ii) to reach the real dimension of the organ by adding volume, iii) to get an easy-to-manipulate model thus facilitating learning of spatial visualization. Moreover, the rigid model was intended to place different elements simulating anatomical structures such as the greater omentum (by using a plastic mesh), and the grooves and vessels of the rumen (by using adhesive tape). Students of the first year at the subject of Anatomy and Embryology were asked to take part in the experiment on a voluntary basis, prior to the entrance to the practical sessions. All of them (134 students) participated. Students had completed the lectures on the digestive system of ruminants ( 2 hours) and were ready to take the practical sessions on ruminant stomach anatomy. The practical sessions (2 hours) were designed as follow: during the first 10 minutes students were informed about and recruited for the test; then the students spent about 70 minutes studying real stomachs with teacher supervision; then, during 30 minutes, recruited 
students (all of them) studied on the 3D-printed model by their owns, and finally, during the last 10 minutes completed the surveys.

Survey Record. All the students enrolled in the Anatomy course participated in the survey (134 students). The survey inquired about the effectiveness of 3D-printed models as a viable alternative to traditional approaches to anatomy teaching and learning (Tabla II). The inquiry is composed of 15 questions. Each question from 1 to 13 had a one chosen numeric option, in a scale from 1 to 5 , being 1 the lowest value and 5 the more positive one. Questions 14 and 15 could be evaluated with Yes or No.

Data analysis. Survey data of 1st to 13th questions were analysed by Kruskall-Wallis ( $\mathrm{p} \leq 0.05$ ). Ho (null hypothesis) was 'natural stomach is the suitable manner of teaching' and $\mathrm{H} 1$ was ' $3 \mathrm{D}$-printed model is more suitable to teaching than the natural stomach'. The acceptance level for each survey respondent was the total sum of their answers. The acceptance level was categorised in 5 groups. The groups were the following: group 1 (acceptance $\leq 25$ ), group 2

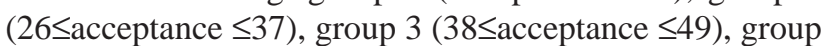

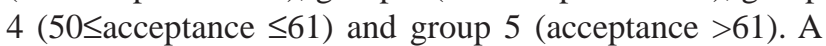
percentage of survey respondents was obtained for each category. The neutral acceptance was in group 2 .

\section{RESULTS}

Anatomical comparison between the real and the 3Dprinted stomachs. Before 3D printing, the ovine stomach model was split transversally off into two halves (cranial and caudal) and glued after printing. This decision allowed to print a model with the real dimension of the organ.

Figure 1 shows the comparison between the 3Dreconstructed stomach (A) and the 3D-printed model (B). The four different compartments of the ovine stomach are easily identified on the 3D-printed model and all of them keep correspondence of size and volume. Position of the esophagus and the duodenum are also equivalent between real and printed organs. Some anatomical details were intentionally remarked on the surface of the 3D-printed model, such as the grooves of the rumen: longitudinal (left and right), cranial, caudal, accessory (left and right) and ruminoreticular grooves.

In order to facilitate comprehension of grooves of the rumen, adhesive tape was stuck on the 3D-printed model thus also resembling the route of vessels (Fig. 2, top). This, in addition, resulted in a more detailed understanding of both boundaries among compartments and the island of the rumen (Insula ruminis).

The complex anatomical relationship of the rumen with the greater omentum was explained on the 3D-printed model (Fig. 2, bottom). A plastic mesh was used to resemble the greater omentum and its division into the superficial wall (Paries superficialis) and the deep wall (Paries profundus). The former is inserted on the left longitudinal groove, and the latter is inserted either on the right longitudinal groove or on the right accessory groove. These two walls (superficial and deep) delimit two different spaces inside the abdominal cavity, the omental bursa (Bursa omentalis), which contains the ventral sac of the rumen, and the supraomental recess (Recessus supraomentalis), containing the intestinal mass. These structures were also shown and explained to students on the 3D-printed model.

Table II. Students`survey to measure the educational value of the 3D printed models. Range: $1-5$ (1=strongly disagree; $2=$ disagree; $3=$ neutral; $4=$ agree; $5=$ strongly agree).

1 The anatomical features in the 3D-printed models are accurate.

2 Size and volume of the organ are easier unders tood on the 3D-printed model.

3 The different compartments of the stomach are easier understood on the 3D-printed model.

$4 \quad$ S acs and grooves of the rumen are easier understood on the 3D-printed model.

5 Topographical relationships of nearby structures (such as the greater omentum) are more readily appreciated with the 3Dprinted model.

6 Compared with the real organ, the color of the 3D-printed model does not make more difficult to learn the anatomy.

7 Compared with the real organ, the texture of the 3D-printed model does not make more difficult to leam the anatomy.

8 Compared with the real organ, the rigidity of the 3D-printed model does not make more difficult to learn the anatomy.

9 Hand-on manipulation is easier with the 3D-printed model.

10 I would use again only the 3D-printed model for studying anatomy.

11 The 3D-printed model is preferred to real organs for examination.

12 The 3D-printed model is preferred to anatomical images for examination.

13 The 3D-printed model can replace real specimens in anatomy learning.

14 The 3D-printed model is useful for the study of subjects different from anatomy.

15 I am willing to purchase the 3D-printed model for studying. 

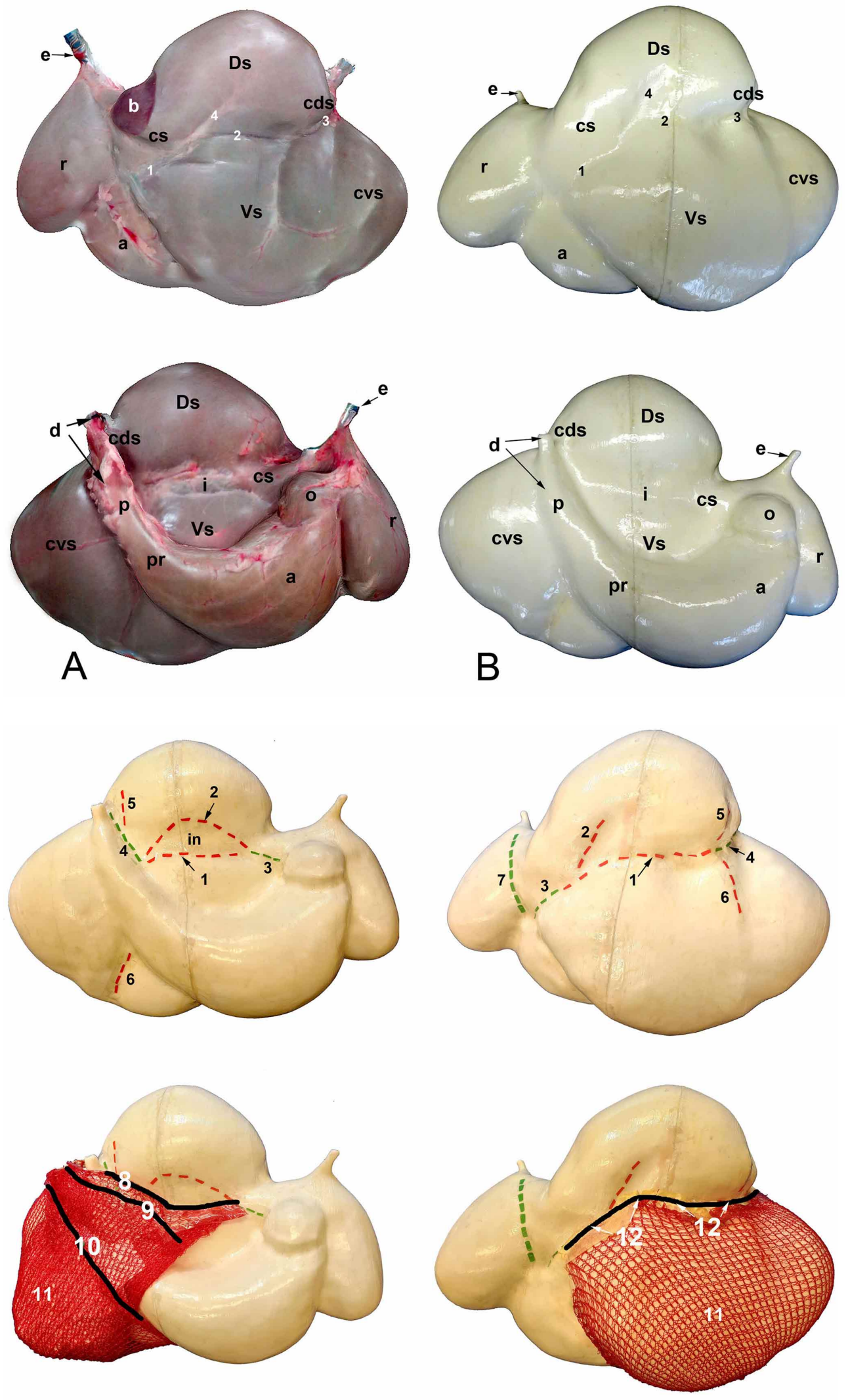

A
Fig. 1. Left (top) and Right (bottom) views of the ovine stomachs; (A) 3D reconstruction after surface scanning; (B) 3D- printed model. e: esophagus; b: spleen (only on the real organ, absent in the printed model); r: reticulum; Ds: dorsal sac of the rumen; Vs: ventral sac of the rumen; cs: cranial sac of the rumen (atrium); cds: caudodorsal blind sac; cvs: caudoventral blind sac; 1 : cranial groove; 2: left longitudinal groove; 3 : caudal groove; 4: left accessory groove; i: island of the rumen; o: omasum; a: abomasum (body); pr: piloric region of the abomasum; p: pylorus; $\mathrm{d}$ : cranial duodenum.

Fig. 2. 3D-printed ovine stomachs. (Top) Schematic representation of ruminal grooves and the vessels they contain.

(Bottom)

Representation of the walls of the greater omentum (superficial and deep); (A) Right views of the stomach; (B) Left views of the stomach. 1: longitudinal grooves; 2: accessory grooves; 3 : cranial groove; 4: caudal groove; 5: caudodorsal groove; 6: caudoventral groove; 7: ruminoreticular groove; 8: insertion of the deep wall on the right longitudinal groove of the rumen; 9: opposite edge of the deep wall after folding; 10: edge of the superficial wall; 11: superficial wall; 12 : insertion of the superficial wall on the left longitudinal groove of the rumen. It is shown to the students that intestinal mass occupies the space between 8 and 9 (the supraomental recess). 

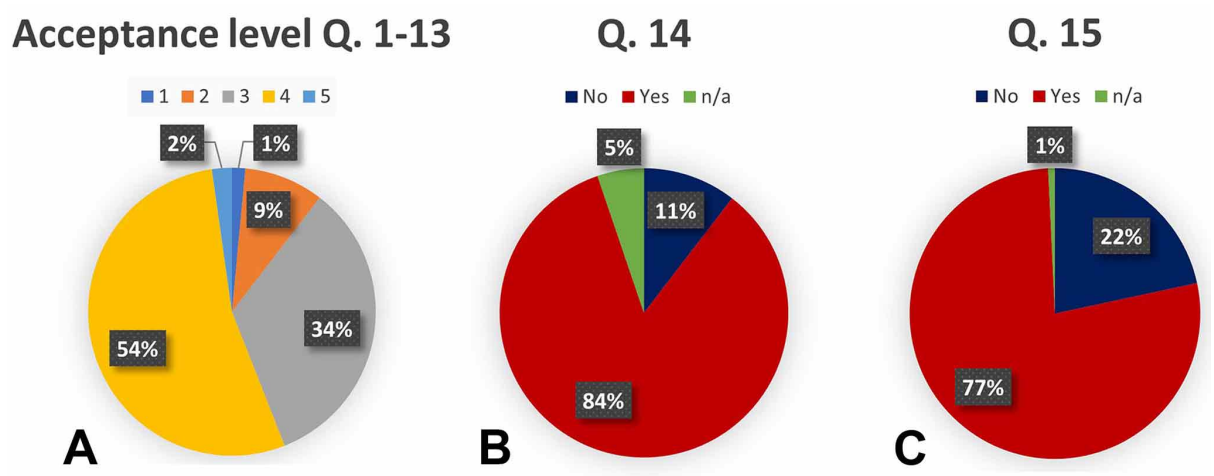

Fig. 3. Percentage breakdown describing A) level of acceptance of questions 1-13, B) and C) the chosen answers for questions 14 and 15 , respectively.

Survey analysis. All participants completed all questions $(13+2)$ in the survey. Value of acceptance of the 3D-printed model was $88 \%$ (Fig. 3A). In a scale from 1 to 5 (being 3 neutral) the $89 \%$ of students agreed (4)/strongly agreed (5) that anatomical features in the given 3D-printed model are accurate (Fig. 4); $75 \%$ felt that size and volume are better understood (Fig. 4); $72 \%$ that topography of the organ is easier to understand compared to real specimens (Fig. 4); at this regard free comments and discussion with the students showed the 3D-printed model to be absolutely convenient for teaching the insertions and configuration of the greater omentum. The ease of manipulation of the 3D-printed model was another remarkable characteristic, defended by $77 \%$ of students (Fig. 4). The use of the 3D-printed model in the practical exams of Anatomy had an equal acceptance (52 $\%)$ to real specimens, and a high acceptance $(80 \%)$ compared with anatomical images (Fig. 4).

Students were asked for the physical features of the 3D-printed model, such as rigidity, texture, and color; $62 \%$ of students felt that these features did not interfere with

learning at all, whereas $15 \%$ observed physical characteristics of 3D-printed stomachs as negative, not contributing to enhance fidelity (Fig. 4).

Students expressed the view that the 3D-printed model did not substitute the real organ for the study. Up to $66 \%$ of students rejected the idea of using only 3D-printed models for studying, and only $7 \%$ of students would prefer 3D-printed models of the ovine stomach, instead of real organs.

Finally, students were willing to use the anatomy model for studying other subjects $(84 \%)$ and even to purchase it $(77 \%)$ as long as the cost is reasonably low (Figs. $3 \mathrm{~B}, \mathrm{C})$.

\section{DISCUSSION}

This study reports the 3D- manufacturing of an ovine stomach by surface scanning and FDM technology and presents evaluation of the perceived educational value of

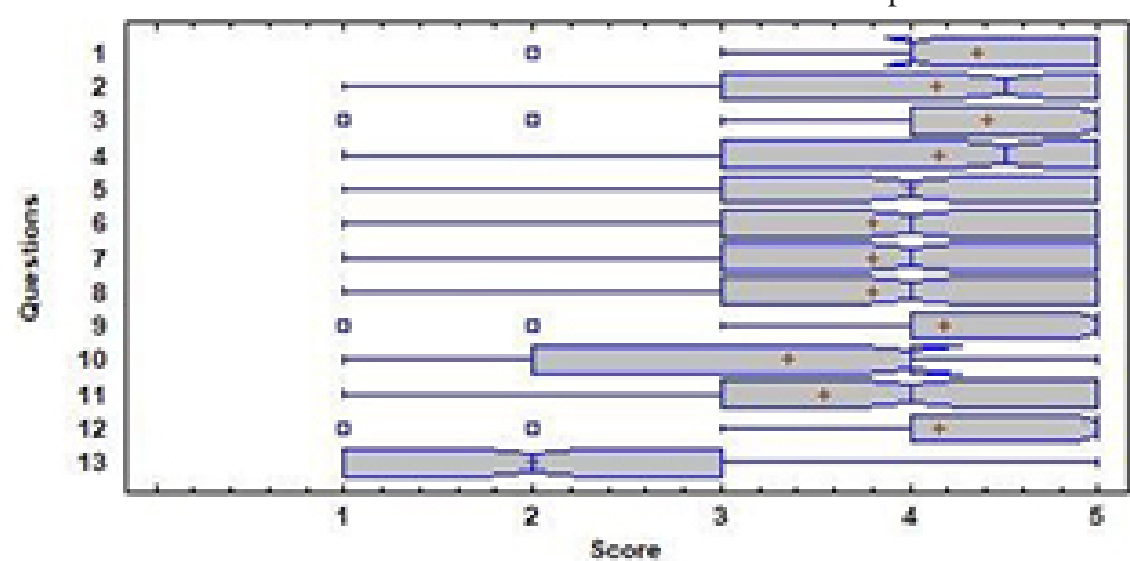

Fig. 4. Plot- and whisker- diagram for each question (Y-axis) and its score (X-axis). The mean is represented as a cross, the median as a transversal line in the bar, and squares are the lower outliers. Whiskers indicating variability outside the upper and lower quartiles. the 3D-printed model of the stomach for the learning of surface and topographical anatomy, comparing with the real organ. It has been reported that physical rigid models are good at showing surface anatomical details but not able both to provide equal handson experience, and to display deeper anatomical features (Mashiko et al., 2015). In our experience, surface detail accuracy is not by far the best advantage of a rigid 3D-printed model obtained by surface scanning. A few others can be listed: the ease to manipulate; the possibility to faithfully reproduce the real size and volumen; 
and what we consider the two most valuable characteristics: improvement of comprehension of spatial visualization of anatomical relationships (Preece et al.) and the possibility of customization (Ventola, 2014; Rengier et al., 2010; DiDonato et al.). For example, we decided to add stickers on the model to display grooves and vessels in the rumen. With the help of a plastic mesh, students were shown the arrangement of the greater omentum and its relationship with the rumen. In fact, we realized that the success of our 3Dprinted model relied on the capacity of interaction, and the easy understanding of anatomical relationships. Nearly all the students felt that anatomical features in the 3D-printed ovine stomachs were accurate and benefited their learning of anatomy. The 3D-printed models were especially useful in improving spatial ability. The importance of visualization and visual learning in anatomy has been largely explored in undergraduate education (Berney et al., 2015; Gutierrez et al., 2017; Keenan \& Ben Awadh). We think that the reason why 3D-printed models improved understanding of topographical anatomy of the ovine stomach is that manipulation of the physical model provided the students a visual and tactile feedback of size and volume, difficult to achieve with real specimens. Tactile experience has been considered an important factor during anatomy learning (Mogali et al., 2018). Students appreciated the ease to manipulate and rotate the model, thus avoiding the concern of damage. In fact, the limitation of manipulation has been reported to have a negative impact on learning either with fresh specimens or with plastinated prosections (McMenamin et al., 2014; Mogali et al.). In line with previous studies (Schoenfeld-Tacher et al.) additional benefits of our 3D-printed model were the increased durability (it has been used for two years with no damage at all), the decreased production costs, and the overall reduction in the use of animal tissues.

It was important to us verify that the use of the artificial 3D-model would not have any negative impacts on veterinary students' learning of anatomy. The answer to this question is gathered from questions 6 to 8 in the survey. Most of the students felt that knowledge achievement was adequate with the 3D-printed model. Physical factors such as color, texture and hardness did not appear as drawbacks during the learning process. This finding goes in line with numerous experiences on which physical anatomical models in $3 \mathrm{D}$ representation were highly effective in gross anatomy learning (Yammine \& Violato).

Interestingly, in spite of the advantages described, only half of the participants would use the 3D-printed model instead of the real organ; and only $7 \%$ of students opined that 3D-printed ovine stomach could replace real organs during the study of anatomy. Examination of real specimens appears to be essential for the students' anatomical study. Therefore, 3D-printed models appear rather as a complement than a substitute of real organs (Smith et al., 2018). A combination of 3D-printed models and real specimens may prove to be the most viable alternative to accomplish the anatomical study of the ovine stomach. Due to the experience of real anatomy is unique (hands-on tactile experience, the respect for the cadaveric material, low confidence in 3Dmodel reproduction) numerous studies on anatomy learning through 3D-printed models agree to combine both models real and artificial (Mcmenamin et al.; Ho et al., 2017; Mogali et al.) as long as the cadaveric material is accessible, therefore the artificial models could just substitute real specimens when is not. Questions 14 and 15 in the survey were intended to reflect the student's interest on the anatomy model beyond its use in anatomy classes. Most students felt that the 3Dprinted model would be useful for studying other subjects (in the discussion out of the survey students mentioned physiology, clinical examination, pathology of ruminants, surgery) and accepted the idea of acquiring it at reasonable prices. This result reflects the growing interest of 3D-printed anatomy models in education, and their transversal character, being able to offer a diverse range of user interaction (Azer \& Azer; Smith \& Jones, 2018; Ford \& Minshall) and multiple applications within the clinical context (Rengier et al.; Favier et al., 2017; Raffan et al.; Zheng et al., 2019; da Neves et al., 2020).

\section{CONCLUSION}

The three-dimensional printed model of the ovine stomach by surface scanning appears as an useful simple tool to complement the learning of surface and topographical anatomy, providing easy user interaction and inexpensive costs.

ACKNOWLEDGEMENTS. Authors thank comments from anonymous reviewers.

MENDAZA-DECAL, R. M. \& ROJO, C. Modelo impreso en 3D del estómago ovino mediante escaneo de superficie: evaluación para la enseñanza de anatomía veterinaria. Int. J. Morphol., 39(5):14801486, 2021.

RESUMEN: Este estudio investigó el uso de modelos de modelos tridimensionales (3D), impresos mediante deposición fundida (FDM) del estómago ovino para aprender su anatomía superficial y topográfica. Los objetivos fueron: i) reproducir la morfología externa, el volumen normal y el correcto posicionamiento de los cuatro compartimentos del estómago ii) facilitar al alumno la visualización 
espacial del órgano con énfasis en la compleja relación estómagoomento mayor. El modelo se construyó basándose en un escaneo de superficie. Para obtener las imágenes, se escaneó el estómago ovino utilizando un escáner de superficie 3D. La evaluación del modelo se realizó mediante encuestas a estudiantes de primer año de veterinaria después de las sesiones prácticas en las que estudiaron y compararon especímenes tanto reales como impresos en 3D. En cuanto a la morfología, no se observaron diferencias significativas, los estudiantes fueron igualmente capaces de identificar las diferentes estructuras y compartimentos en el modelo impreso en 3D. La comprensión de la posición espacial y la relación del estómago con las estructuras anatómicas vecinas se logró más fácilmente con el modelo impreso en 3D. Otras ventajas del modelo impreso en 3D fueron la resistencia y facilidad de manejo, la disponibilidad y la reducción del uso de muestras de animales. Proponemos que el estómago ovino impreso en 3D mediante escaneo de superficie es un modelo simple y valioso para apoyar el aprendizaje de la anatomía superficial y topográfica.

PALABRAS CLAVE: Escaneo de impresión 3D; Estómago ovino; Anatomía veterinaria.

\section{REFERENCES}

Azer, S. A. \& Azer, S. 3D Anatomy models and impact on learning: a review of the quality of the literature. Health Prof. Educ., 2(2):80-98, 2016.

Berney, S.; Bétrancourt, M.; Molinari, G. \& Hoyek, N. How spatial abilities and dynamic visualizations interplay when learning functional anatomy with 3D anatomical models. Anat. Sci. Educ., 8(5):452-62, 2015.

das Neves, E. C.; Pelizzari, C.; de Oliveira, R. S.; Kassab, S.; Lucas, K. A. \& de Carvalho, Y. K. 3D printed anatomical model for teaching canine lumbosacral epidural anesthesia. Acta Cir. Bras., 35(6):e202000608, 2020.

Di-Donato, B. A.; dos-Santos, A. C.; da Silveira, E. E.; Pereira, H. C. S.; da Silva Lisboa-Neto, A. F.; de Oliveira Alcobaça, M. M. \& de de AssisNeto, A. C. Three-dimensional digitalized and printed tongue models of the cow, dog, pig and horse for undergraduate veterinary education. Int. J. Morphol., 39(2):436-40, 2021.

Favier, V.; Zemiti, N.; Caravaca Mora, O.; Subsol, G.; Captier, G.; Lebrun, R.; Cramprette, L.; Mondain, M. \& Gilles, B. Geometric and mechanical evaluation of 3D-printing materials for skull base anatomical education and endoscopic surgery simulation - A first step to create reliable customized simulators. PLoS One, 12(12):e0189486, 2017.

Ford, S. \& Minshall, T. Invited review article: Where and how 3D printing is used in teaching and education. Addit. Manuf., 25:131-50, 2019.

Gutierrez, J. C.; Chigerwe, M.; Ilkiw, J. E.; Youngblood, P.; Holladay, S. D. \& Srivastava, S. Spatial and visual reasoning: Do these abilities improve in first-year veterinary medical students exposed to an integrated curriculum? J. Vet. Med. Educ., 44(4):669-75, 2017.

Hackmann, C. H.; Dos-Reis, D. A. L. \& De-Assis-Neto, A. C. Digital revolution in veterinary anatomy: confection of anatomical models of canine stomach by scanning and three-dimensional printing (3D). Int. J. Morphol., 37(2):486-90, 2019.

Hespel, A. M.; Wilhite, R. \& Hudson, J. Invited review--Applications for $3 \mathrm{D}$ printers in veterinary medicine. Vet. Radiol. Ultrasound, 55(4):34758, 2014.

Ho, D.; Squelch, A. \& Sun, Z. Modelling of aortic aneurysm and aortic dissection through3D printing. J. Med. Radiat. Sci., 64(1):10-7, 2017.

International Committee on Veterinary Gross Anatomical Nomenclature (ICVGAN). Nomina Anatomica Veterinaria. 6th ed. Hanover, World Association of Veterinary Anatomists, 2017.
Keenan, I. D. \& Ben Awadh, A. Integrating 3D visualisation technologies in undergraduate anatomy education. Adv. Exp. Med. Biol., 1120:3953,2019

König, H. \& Liebich, H. Anatomía de los Animales Domésticos. Texto y Atlas en Color. Vol. 2. Madrid, Médica Panamericana, 2011.

Mashiko, T.; Otani, K.; Kawano, R.; Konno, T.; Kaneko, N.; Ito, Y. \& Watanabe, E. Development of three-dimensional hollow elastic model for cerebral aneurysm clipping simulation enabling rapid and low cost prototyping. World Neurosurg., 83(3):351-61, 2015.

McMenamin, P. G.; Quayle, M. R.; McHenry, C. R. \& Adams, J. W. The production of anatomical teaching resources using three-dimensional (3D) printing technology. Anat. Sci. Educ., 7(6):479-86, 2014.

Mogali, S. R.; Yeong, W. Y.; Tan, H. K. J.; Tan, G. J. S.; Abrahams, P. H.; Zary, N.; Low-Beer, N. \& Ferenczi, M. A. Evaluation by medical students of the educational value of multi-material and multi-colored three-dimensional printed models of the upper limb for anatomical education. Anat. Sci. Educ., 11(1):54-64, 2018.

Nickel, R.; Schummer, A. \& Seiferle, E. The Viscera of the Domestic Mammals. Hamburg, Verlag Paul Parey, 1979.

Preece, D.; Williams, S. B.; Lam, R. \& Weller, R. "Let's get physical": advantages of a physical model over 3D computer models and textbooks in learning imaging anatomy. Anat. Sci. Educ., 6(4):216-24, 2013.

Raffan, H.; Guevar, J.; Poyade, M. \& Rea, P. M. Canine neuroanatomy: Development of a 3D reconstruction and interactive application for undergraduate veterinary education. PLoS One, 12(2):e0168911, 2017.

Rengier, F.; Mehndiratta, A.; von Tengg-Kobligk, H.; Zechmann, C. M.; Unterhinninghofen, R.; Kauczor, H. U. \& Giesel, F. L. 3D printing based on imaging data: review of medical applications. Int. J. Comput. Assist. Radiol. Surg., 5(4):335-41, 2010.

Schoenfeld-Tacher, R. M.; Horn, T. J.; Scheviak, T. A.; Royal, K. D. \& Hudson, L. C. Evaluation of 3D additively manufactured canine brain models for teaching veterinary neuroanatomy. J. Vet. Med. Educ., 44(4):612-9, 2017.

Smith, C. F.; Tollemache, N.; Covill, D. \& Johnston, M. Take away body parts! An investigation into the use of 3D-printed anatomical models in undergraduate anatomy education. Anat. Sci. Educ., 11(1):44-53, 2018

Smith, M. L. \& Jones, J. F. X. Dual-extrusion 3D printing of anatomical models for education. Anat. Sci. Educ., 11(1):65-72, 2018.

Thomas, D. B.; Hiscox, J. D.; Dixon, B. J. \& Potgieter, J. 3D scanning and printing skeletal tissues for anatomy education. J. Anat., 229(3):473$81,2016$.

Ventola, C. L. Medical applications for 3D printing: current and projected uses. P. T., 39(10):704-11, 2014.

Wilhite, R. \& Wölfel, I. 3D Printing for veterinary anatomy: An overview. Anat. Histol. Embryol., 48(6):609-20, 2019.

Yammine, K. \& Violato, C. The effectiveness of physical models in teaching anatomy: a meta-analysis of comparative studies. Adv. Health Sci. Educ. Theory Pract., 21(4):883-95, 2016.

Zheng, B.; Wang, X.; Zheng, Y. \& Feng, J. 3D-printed model improves clinical assessment of surgeons on anatomy. J. Robot. Surg., 13(1):617, 2019.

Corresponding author:

Concepción Rojo Salvador

Sección Departamental de Anatomía y Embriología

Facultad de Veterinaria

Universidad Complutense de Madrid

Avda. Puerta de Hierro S/N 28040

Madrid- ESPAÑA

E-mail: crojosal@ucm.es

Received: 11-06-2021

Accepted: 17-07-2021 